\title{
Transplantation of Hypoxic-Preconditioned Bone Mesenchymal Stem Cells Retards Intervertebral Disc Degeneration via Enhancing Implanted Cell Survival and Migration in Rats
}

\author{
Weiheng Wang, ${ }^{1}$ Yang Wang, ${ }^{2}$ Guoying Deng, ${ }^{3}$ Jun Ma, ${ }^{1}$ Xiaodong Huang, ${ }^{1}$ Jiangming Yu, ${ }^{1}$ \\ Yanhai Xi, ${ }^{1}$ and Xiaojian Ye ${ }^{1}{ }^{1}$ \\ ${ }^{1}$ Department of Orthopaedics, Changzheng Hospital, Second Military Medical University, Shanghai 200003, China \\ ${ }^{2}$ Department of Orthopaedics, Nanjing General Hospital, Nanjing 210000, China \\ ${ }^{3}$ Trauma Center, Shanghai General Hospital, Shanghai Jiao Tong University School of Medicine, Shanghai 201620, China
}

Correspondence should be addressed to Xiaojian Ye; xjyespine@smmu.edu.cn

Received 12 September 2017; Revised 13 November 2017; Accepted 22 November 2017; Published 14 February 2018

Academic Editor: Kivanc Atesok

Copyright (C) 2018 Weiheng Wang et al. This is an open access article distributed under the Creative Commons Attribution License, which permits unrestricted use, distribution, and reproduction in any medium, provided the original work is properly cited.

\begin{abstract}
Objective. Special hypoxic and hypertonic microenvironment in intervertebral discs (IVDs) decreases the treatment effect of cell transplantation. We investigated the hypothesis that hypoxic preconditioning (HP) could improve the therapeutic effect of bone mesenchymal stem cells (BMSCs) to IVD degeneration. Methods. BMSCs from green fluorescent protein-transgenic rats were pretreated with cobalt chloride $\left(\mathrm{CoCl}_{2}, 100 \mu \mathrm{M}, 24 \mathrm{~h}\right)$ for hypoxic conditions in vitro. Apoptosis (related pathways of caspase-3 and bcl-2) and migration (related pathways of HIF- $1 \alpha$ and CXCR4) were detected in BMSCs. In vivo, BMSCs and HP BMSCs (H-BMSCs) were injected into the rat model of IVD degeneration. The IVD height, survival, migration, and differentiation of transplanted BMSCs and matrix protein expression (collagen II, aggrecan, and MMP-13) were tested. Results. H-BMSCs could extensively decrease IVD degeneration by increasing IVD height and collagen II and aggrecan expressions when compared with BMSCs. Significantly, more GFP-positive BMSCs were observed in the nucleus pulposus and annulus fibrosus regions of IVD. HP could significantly decrease BMSC apoptosis (activating bcl-2 and inhibiting caspase-3) and improve BMSC migration (increasing HIF- $1 \alpha$ and CXCR4) in vitro. Conclusion. HP could significantly enhance the capacity of BMSCs to repair DDD by increasing the survival and migration of implanted cells and increasing matrix protein expression.
\end{abstract}

\section{Introduction}

According to statistics, $70 \%$ of the population will be plagued by lower back pain in life caused by disc degeneration disease (DDD), which leads to a serious public health problem [1-3]. Surgery may be able to alleviate clinical symptoms, although it is unable to eliminate the degeneration of intervertebral discs (IVDs) $[4,5]$. Disc degeneration is characterized by a reduction of nucleus pulposus cells (NPCs) and their extracellular matrix (ECM), and NPCs are replaced by cells of a more fibroblast-like phenotype in the degenerated IVDs [6]. Curative treatment for DDD is a major challenge because of limited regeneration of the IVD itself.

Cell transplantation has emerged as an effective therapy for DDD in recent decades [7]. Bone mesenchymal stem cells
(BMSCs) hold great promise in IVD regeneration [8-11]. BMSCs are pluripotent and multipotent and possess the capabilities of self-renewal and differentiation into specific cell lineages [12-16]. However, there are hurdles that need to be removed before BMSC transplantation for clinical applications. IVD is the largest avascular tissue in the human body, and nutrition renewal can only be completed through passive diffusion $[17,18]$. Due to the lack of blood vessels and the special hypertonic and hypoxic environment of IVDs $[19,20]$, the survival rate and repair ability of transplanted stem cells cultured under common culture conditions are poor $[21,22]$. As the hypertonic and hypoxic environment can reduce activity and vitality of transplanted stem cells $[23,24]$, a way to bolster the transplanted stem cell survival and treatment effects is needed urgently. 
Hypoxic preconditioning (HP) is a powerful, endogenous protective mechanism, which can enhance cell tolerance to subsequent injury and therapy ability [25]. Some studies have shown that HP can effectively improve the transplanted stem cell survival and treatment in myocardial infarction [26] and cerebral infarction [27, 28] animal models. The possible mechanisms of time- and concentration-dependent HP include regulating intracellular transduction, increasing cell resistance to injury, upregulating migration and differentiation, and enhancing growth factor secretion [28-32]. Given the benefits of HP and the special hypertonic and hypoxic environment of IVDs, we supposed the hypothesis that HP might be a feasible and effective way to improve the therapeutic effect of BMSCs to retard IVD degeneration via enhancing implanted cell survival and migration in rats.

The HP conditions were confirmed by a gradient experiment before transplantation, and then the changes of the hypoxic signal pathway, apoptosis and migration ability, and related molecular mechanism in BMSCs were detected in vitro. BMSCs and HP BMSCs (H-BMSCs) were transplanted into degenerated IVD rat model to verify the role of HP on cell survival and therapeutic effect in vivo.

\section{Materials and Methods}

2.1. Animals and Establishment of the DDD Model. SpragueDawley (SD) rats (males, 3 months old) and green fluorescent protein- (GFP-) transgenic male SD rats (SD-Tg (CAG-EGFP) CZ-004Osb, Sina-British SIPPR/BK Lab, Animal Ltd., China) purchased from the Experimental Animal Center of Second Military Medical University were used in this study. The rats' skeleton reached maturity at 3 months, and the IVD remodeling proved irrelevant to rat growth [33]. All procedures were approved by the Institutional Animal Care and Use Committee. The DDD model was established as described by Rousseau et al. [34]. Briefly, a longitudinal incision, approximately $2 \mathrm{~cm}$, was made along the tail to expose the lateral portion of the tail discs, Co5/Co6 and $\mathrm{Co6} / \mathrm{Co} 7$, and then a 21-gauge needle was inserted $1.5 \mathrm{~mm}$ into the disc to aspirate an identical defined volume of the nucleus pulposus material. Radiographic images were captured to ensure that the needle was parallel to the endplates to avoid endplate damage.

2.2. BMSC Culture and Hypoxia Protocol. The extraction and purification of BMSCs from GFP transgenic rats were performed based on a previous study [35]. BMSCs were passaged when cell fusion rate was between $70 \%$ and $80 \%$. The purity of 3 generation (P3) BMSCs were identified by CD29 (FITC), CD90 (PE), CD45 (APC), and CD31 (PE, Guge, Nanjing, China) by flow cytometry (FCM, Beckman, CA, USA). Alizarin red and oil red O (Sigma, MO, USA) were used to examine the osteogenic and adipogenic properties of P3 BMSCs. P3 BMSCs were cultured in fresh complete medium and were added to different concentrations of cobalt chloride $\left(\mathrm{CoCl}_{2}\right)$ for $6,12,24$, and $48 \mathrm{~h}$. The $\mathrm{CoCl}_{2}$ concentration in the complete medium was maintained at 0,10 , $50,100,200$, and $300 \mu \mathrm{M}$.
2.3. Detection of the Influence of HP on BMSC Proliferation by CCK-8. P3 BMSCs were inoculated into 96-well plates $\left(5 \times 10^{3}\right.$ cells/well with $100 \mu \mathrm{L}$ of complete culture medium), and after the cells adhered to the walls, different intervention culture mediums were replaced: the complete culture medium for cells containing $0,10,50,100,200$, and $300 \mu \mathrm{M}$ $\mathrm{CoCl}_{2}$ were cultured for $6,12,24$, and $48 \mathrm{~h}$. The proliferation of BMSCs was detected using $450 \mathrm{~nm}$ ultraviolet ray by a microplate reader (Bio Tek, Vermont, USA) by using a CCK-8 kit (Biyuntian, Jishou, China) according to the manufacturer's instructions. The experiment was repeated 3 times with 3 repeated wells per concentration.

2.4. Detection of the Influence of HP on BMSC Migration by Transwell Assay. In this experiment, we used polycarbonate inserts (pore size $8.0 \mu \mathrm{m}$, Millipore, Massachusetts, USA) to establish a migration model in a transwell system. The transwell method was conducted according to the manufacturer's instructions. The experiment was divided into BMSC group and H-BMSC group. P3 BMSCs were pretreated with complete medium for $24 \mathrm{~h}$ in BMSC group, while P3 BMSCs were pretreated with $100 \mu \mathrm{M} \mathrm{CoCl}$ for $24 \mathrm{~h}$ in the $\mathrm{H}$-BMSC group. Then, cells were cultured in a transwell system with complete medium. Transwell inserts were removed after culturing for 6,12 , and $24 \mathrm{~h}$. The cells were washed with $0.01 \mathrm{M}$ phosphate-buffered saline (PBS) 3 times and fixed with $4 \%$ paraformaldehyde for $30 \mathrm{~min}$. Then, the migrated BMSCs were stained with $0.1 \%$ crystal violet (Guge, Wuhan, China) for $20 \mathrm{~min}$. The images were captured with a microscope (Olympus, Tokyo, Japan). Five horizons were selected randomly for cell counting. The experiment was repeated 3 times with each using 3 repeated wells.

2.5. Detection of the Influence of HP on BMSC Tolerance to Apoptotic Insult by FCM. According to the results of cell proliferation, $100 \mu \mathrm{M} \mathrm{CoCl}$ for $24 \mathrm{~h}$ was selected for the HP conditions. P3 BMSCs were inoculated into 6-well plates at a density of $1 \times 10^{5}$ cells/well and cultured for $24 \mathrm{~h}$. The adherent cells were collected, and the apoptosis rate was detected by FCM by using the annexin V-PI kit (BD, New Jersey, USA). Then, we challenged the BMSCs with serum deprivation for $24 \mathrm{~h}$. Adherent cell apoptosis was detected by FCM to study the BMSC tolerance to serum deprivation. All procedures were carried out according to the manufacturer's instructions. The experiment was repeated 3 times with each using 3 repeated wells.

2.6. Detection of the Influence of HP on BMSC $m R N A$ Expression by RT-PCR. The influence of HP on the expression of BMSC migration-related genes (HIF- $1 \alpha$ and CXCR4) and apoptosis-related genes (caspase-3 and bcl-2) was detected. P3 BMSCs were cultured in 6-well plates for $24 \mathrm{~h}$ at 0 and $100 \mu \mathrm{M} \mathrm{CoCl}$. Then, BMSCs were challenged with serum deprivation for $24 \mathrm{~h}$. Total mRNA was extracted using isogen reagent and suggested protocols (Nippon Gene, Tokyo, Japan). RNA samples were then reverse transcribed to cDNA, followed by specific amplification of matrixspecific genes and electrophoretic separation. The mRNA expression of target genes was normalized to that of GAPDH. 
The experiment was repeated 3 times. The primers were synthesized by Shenggong Biomedical Engineering (Shanghai, China, Table 1).

2.7. The Administration of BMSCs. Forty SD rats were randomly divided into 4 groups: the sham group, control group, BMSC group, and H-BMSC group $(n=10)$. In the sham group, incisions were made without inserting a needle. Rats in the control, BMSC, and H-BMSC groups were inserted with a 21-gauge needle. After 2 weeks, cell transplantation into $\mathrm{Co5} / \mathrm{Co6}$ and $\mathrm{Co6} / \mathrm{Co} 7$ discs was performed carefully through a 33-gauge microinjector (Hamilton, Switzerland) for at least $5 \mathrm{~min}$. $2.0 \mu \mathrm{L}$ PBS $(0.01 \mathrm{M})$ was injected in the control group, while P3 GFP-positive BMSCs (BMSC-GFP, $2 \times 10^{4}$ cells) dissolved in $2.0 \mu \mathrm{L}$ PBS were injected in the BMSC group and HP P3 BMSC-GFP $\left(2 \times 10^{4}\right.$ cells $)$ dissolved in $2.0 \mu \mathrm{L}$ PBS were injected in the H-BMSC group. Four weeks after cell transplantation, the IVDs of Co5/Co6 and Co6/Co7 were obtained for the subsequent study.

2.8. Radiographic Analysis. At 1 day before and 2, 4, and 6 weeks after surgery, lateral plain radiographs were taken after anesthesia to keep the caudal muscle relaxed. The disc height was calculated by disc height index (DHI) as described by Lin et al. [36]. Changes in DHI were expressed as \% DHI and normalized to the measured preoperative IVD height (\% $\mathrm{DHI}=$ postoperative $\mathrm{DHI} /$ preoperative $\mathrm{DHI} \times 100, n=10)$. Changes in IVD height at different weeks were analyzed by Sante DICOM free software. All images were measured by 3 independent observers who were blind to the specimens.

2.9. Evaluation Survival, Migration, and Differentiation of Transplanted BMSCs. Four weeks after cell transplantation, Co6/Co7 discs were harvested and processed individually in Tissue-Tek O.C.T. Compound $(n=10)$. The tissues were sectioned with a freezing microtome (LEICA, Germany) in the coronal direction to generate $7 \mu \mathrm{m}$ thick sections. Sections were fixed with $4 \%$ paraformaldehyde and incubated overnight with rabbit anti-rat collagen II $(1: 200$, ab188570, Abcam, USA) and rabbit anti-rat aggrecan $(1: 200,13880-$ 1-AP, Proteintech, USA) primary antibodies at $4^{\circ} \mathrm{C}$. Then, the sections were incubated with the corresponding secondary antibody for $2 \mathrm{~h}$ at room temperature. Cell nuclei were stained by $4^{\prime}, 6^{\prime}$-diamino-2-phenylindole (DAPI, HARVEY, USA). The sections were observed by a fluorescence microscope (Olympus, Tokyo, Japan). 10 fields were randomly selected from each group to calculate the cell-positive rate. The rate of positive cells was calculated as (number of positive cells) $/$ (total number of cells in the field) $\times 100 \%$.

2.10. Changes of Nucleus Pulposus Tissue Matrix Protein (Collagen II, Aggrecan, and MMP-13) Detected by Western Blot. Antibodies of rabbit anti-rat collagen II (ab188570, Abcam, USA), rabbit anti-rat aggrecan (13880-1-AP, Proteintech, USA), and rabbit anti-rat MMP-13 (ab39012, Abcam, USA) were used to detect protein expression in nucleus pulposus tissue by Western blot. Four weeks after cell transplantation, Co5/Co6 discs were harvested $(n=10)$, and the total protein in each sample was determined by the BCA method. Cytosolic fractions were separated by SDS-PAGE, transferred, and immobilized on a nitrocellulose membrane. Using corresponding secondary antibody (1:15,000; Abmart, Shanghai, China) for $2 \mathrm{~h}$ at room temperature, the immune complexes were detected with the ECL chemiluminescence system. Protein from densitometry was quantitatively analyzed with Sigma Scan Pro 5 and normalized to the GAPDH level.

2.11. Statistical Analysis. All results are presented as the mean \pm SD or mean \pm SEM. Data analysis was performed by SPSS 21 software (SPSS Inc., Chicago, USA), and diagrams were drawn by GraphPad Prism 5 software (GraphPad Inc., California, USA). The data was analyzed by repeated measure ANOVA test. $P<0.05$ was considered statistically significant.

\section{Results}

3.1. Characterization of BMSCs. Identification of the morphology, purity, and differentiation of P3 BMSCs was performed. P3 BMSCs were uniform, spindle-shaped, or irregularly refractive (Figure 1(a)). Fluorescence microscopy showed that P3 BMSCs were labeled with green fluorescence (Figure 1(b)). BMSC-GFP expression is driven by the chicken $\beta$-actin promoter and cytomegalovirus enhancer [37] and confirmed to be GFP positive in a previous study [38]. CD29 (+), CD90 (+), CD31 (-), and CD45 (-) were used to detect the purity of $\mathrm{P} 3 \mathrm{BMSC}$ by FCM. The positive rate of CD29, CD90, CD31, and CD45 was $98.8 \%, 91.3 \%, 0.6 \%$, and $2.4 \%$, respectively (Figures $1(\mathrm{e})-1(\mathrm{~h})$ ), which indicated that P3 BMSCs were of high purity. As shown in Figures 1(c) and 1(d), BMSCs had a good ability for osteogenic and adipogenic differentiation. All of these results suggested that the obtained high-purity BMSCs were suitable for cell therapy.

3.2. Influence of HP on BMSC Proliferation. The different concentrations of $\mathrm{CoCl}_{2}$ could decrease proliferation, which correlated with the $\mathrm{CoCl}_{2}$ concentrations and cell culture time (Table 2). When the $\mathrm{CoCl}_{2}$ concentrations were 200 and $300 \mu \mathrm{M}$, the BMSC proliferation was significantly inhibited, and the inhibition extent was more obvious with the extension of culture time $(P<0.05)$. According to the results of CCK-8, the condition of $100 \mu \mathrm{M} \mathrm{CoCl} \mathrm{Cl}_{2}$ at $24 \mathrm{~h}$ was selected as the $\mathrm{HP}$ condition. Under this condition, the influence of HP on BMSC proliferation was significant and acceptable.

3.3. HP Decreased Cell Apoptosis. Apoptosis is a major form of cell death. The apoptosis rate was the early plus late apoptosis rate. FCM detection results were shown after $100 \mu \mathrm{M}$ $\mathrm{CoCl}_{2}$ preconditioned for $24 \mathrm{~h}$; the apoptosis rate of BMSCs was significantly increased (Figures 2(a) and 2(b), $P<0.05$ ), while the rate was less than $10 \%$, which was within the acceptable range. Based on cell viability and apoptosis rate results, $100 \mu \mathrm{M}$ of $\mathrm{CaCl}_{2}$ for $24 \mathrm{~h}$ was selected as the experimental model of chemical HP of BMSCs. Under this condition, HP had a significant influence on BMSC proliferation and apoptosis rate was within an acceptable range. 
TABle 1: Sequences of primers used for RT-PCR.

\begin{tabular}{lrc}
\hline Gene & Forward primer $\left(5^{\prime}-3^{\prime}\right)$ & Reverse primers $\left(5^{\prime}-3^{\prime}\right)$ \\
\hline GAPDH & GCAAGTTCAACGGCACAG & GGCCCCTCCTGTTGTTATGG \\
HIF-1 $\alpha$ & CACTGCACAGGCCACATTCAT & AAGCAGGTCATAGGCGGTTTC \\
CXCR4 & TCCGTGGCTGACCTCCTCTT & CAGCTTCTCGGCCTCTGGC \\
bcl-2 & TCCTTCCAGCCTGAGAGCAACC \\
Caspase-3 & GCGGTATTGAGACAGACAGTGGAAC & CGACGGTAGCGACGAGAGAAG \\
\hline
\end{tabular}

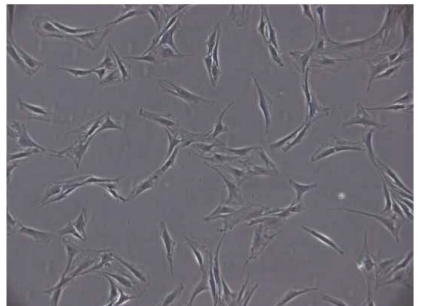

(a)

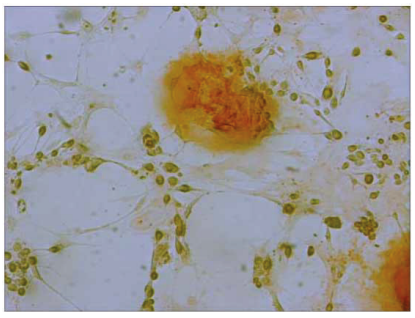

(c)

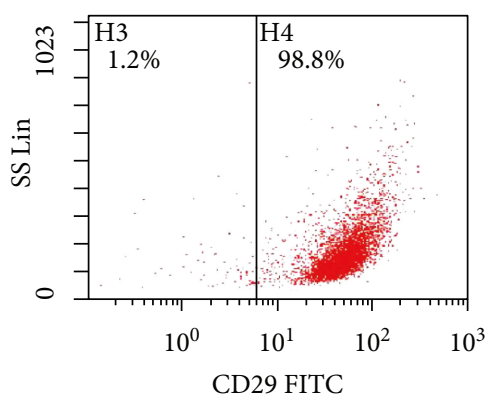

(e)

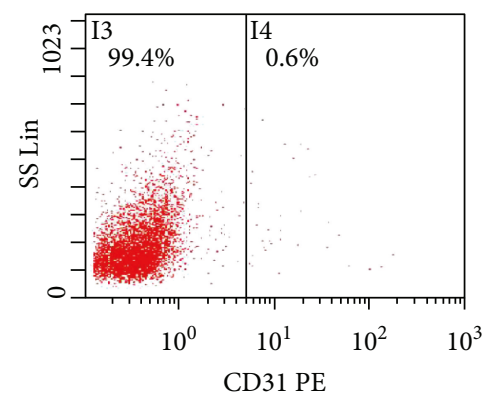

(g)

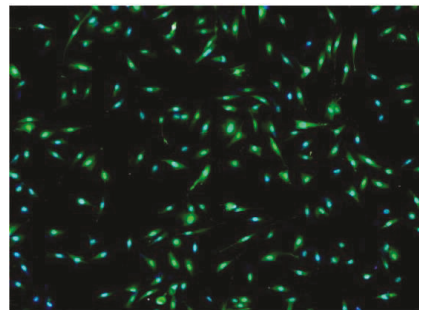

(b)

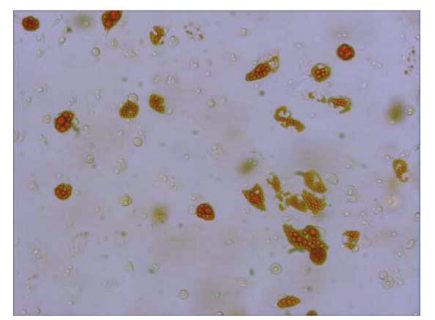

(d)

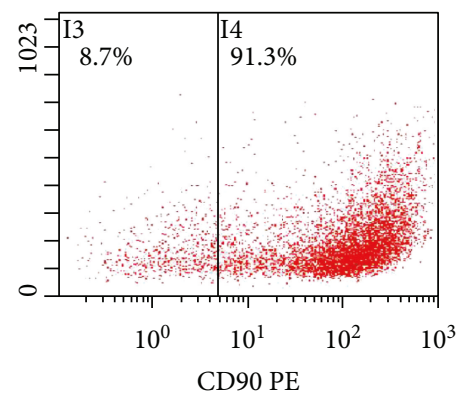

(f)

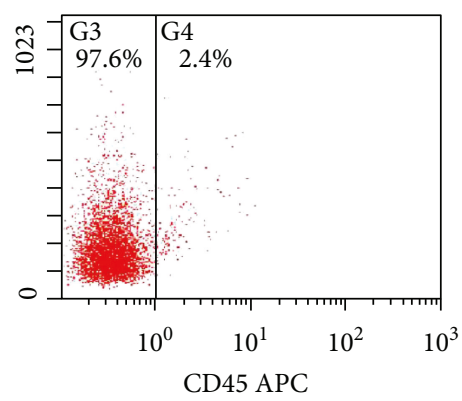

(h)

FIGURE 1: (a) Morphology of BMSCs was observed under microscope (200×). (b) BMSC-GFP displayed green fluorescence and blue nuclei under fluorescence microscopy $(100 \times)$. (c) Osteogenic differentiation of BMSCs: dark brown calcium nodules stained by alizarin red were observed in cells $(400 \times)$. (d) Adipogenic differentiation of BMSCs: brown lipid droplets stained by oil red O were observed in cells $(400 \times)$. (e-h) The P3 BMSC-positive rates of CD29, CD90, CD31, and CD45 were detected by FCM. 
TABLE 2: Effect of $\mathrm{CoCl}_{2}$ on the proliferation of BMSCs detected by CCK- 8 assay.

\begin{tabular}{lcccrc}
\hline Concentration/time & $0 \mathrm{~h}$ & $6 \mathrm{~h}$ & $12 \mathrm{~h}$ & $24 \mathrm{~h}$ & $48 \mathrm{~h}$ \\
\hline $0 \mu \mathrm{M}$ & $1.01 \pm 0.06$ & $1.11 \pm 0.09$ & $1.41 \pm 0.18^{\#}$ & $1.82 \pm 0.19$ & $1.56 \pm 0.18$ \\
$10 \mu \mathrm{M}$ & $1.00 \pm 0.08$ & $1.05 \pm 0.09$ & $1.30 \pm 0.13^{\#}$ & $2.38 \pm 0.10^{\#}$ \\
$50 \mu \mathrm{M}$ & $1.00 \pm 0.09$ & $0.95 \pm 0.12$ & $1.14 \pm 0.18$ & $1.30 \pm 0.12^{*}$ & $1.75 \pm 0.16^{*}$ \\
$100 \mu \mathrm{M}$ & $1.01 \pm 0.10$ & $0.85 \pm 0.14$ & $0.98 \pm 0.12^{\#}$ & $1.15 \pm 0.11$ & $1.41 \pm 0.11^{\#}$ \\
$200 \mu \mathrm{M}$ & $1.03 \pm 0.09$ & $0.80 \pm 0.17$ & $0.88 \pm 0.15$ & $0.95 \pm 0.16^{*}$ & $0.89 \pm 0.13^{*}$ \\
$300 \mu \mathrm{M}$ & $1.01 \pm 0.06$ & $0.72 \pm 0.10$ & $0.58 \pm 0.13$ & $0.44 \pm 0.28$ & $0.24 \pm 0.10$ \\
\hline
\end{tabular}

${ }^{*} P<0.05$ versus $100 \mu \mathrm{M}$ group, ${ }^{\#} P<0.05$ versus $24 \mathrm{~h}$ group (mean $\pm \mathrm{SD}, n=6$ ).

Then, we challenged BMSCs with serum deprivation for another $24 \mathrm{~h}$. FCM detection results showed that HP could sufficiently decrease the BMSC apoptosis rate and increase BMSC tolerance to serum deprivation (Figures 2(c) and 2(d), $P<0.05)$.

3.4. HP Upregulated the Migration of BMSCs. The transwell experiment showed that HP upregulated the migration of BMSCs. There were significantly more cells passing through the membrane in the H-BMSC group after culture for $6 \mathrm{~h}$ (Figures 3(a) and 3(d), $P<0.05$ ) and $12 \mathrm{~h}$ (Figures 3(b) and $3(\mathrm{e}), P<0.05)$ than in the BMSC group. After culture for $24 \mathrm{~h}$, the difference between the two groups was not significant (Figures 3(c) and 3(f), $P>0.1$ ), indicating that most of the BMSCs had passed through the membranes in two groups. HP could significantly increase the migration ability of BMSCs.

3.5. HP Enhances BMSC Migration via HIF-1 $\alpha$ and CXCR4 Pathways and Tolerance to Serum Deprivation by Regulating Bcl-2 and Caspase-3. The BMSC mRNA expression of caspase- 3 , bcl-2, HIF- $1 \alpha$, and CXCR 4 was determined by using RT-PCR. Since caspase- 3 and bcl- 2 activation is a key pathway of apoptosis, we analyzed the mRNA expression to determine whether HP can decrease apoptosis via this pathway. HIF- $1 \alpha$ and its downstream gene, CXCR4, are considered key factors in the role of migration and homing. Therefore, we examined the mRNA content to study whether HP can increase BMSC migration via this pathway. Compared with the BMSC group, the mRNA expression of bcl-2, HIF- $1 \alpha$, and CXCR4 in the H-BMSC group was significantly increased, while the caspase- 3 was significantly decreased (Figure 4, $P<0.05$ ). These results indicated that HP could significantly enhance the BMSC migration via HIF- $1 \alpha$ and CXCR 4 pathways and tolerance to apoptotic insult by regulating bcl-2 and caspase- 3 .

3.6. HP Enhances BMSC Ability of Maintaining IVD Height. Radiography showed that DHI in the sham group did not change significantly $(P>0.1)$. DHI decreased after the induction of IVD degeneration in the control, BMSC, and H-BMSC groups (Figure 5). The mean DHI in the control group continued to decrease until 6 weeks after the induction of IVD degeneration. DHI in the BMSC and H-BMSC groups was much higher compared with that in the control group $(P<0.05)$, and the mean DHI in the H-BMSC group was much higher than that in the BMSC group at 4 weeks after cell transplantation $(P<0.05)$. All these data indicated that BMSC administration could maintain the IVD height, and HP could enhance this ability.

3.7. HP Enhanced BMSC Survival and Migration in Degenerated IVD. BMSC-GFP were detected in IVD after 4 weeks of cell transplantation (Figure 6). There were no GFP-positive cells in the sham and control groups (data not shown). After cell transplantation, BMSC-GFP were mostly distributed in the center of IVD, the density of cells around the transplanted cells was larger, and there was more ECM around the transplanted cells (Figures 6(b), 6(e), and 6(h)) . While in the H-BMSC group, BMSC-GFP were relatively dispersed among the whole IVDs. Some BMSC-GFP migrated into the annulus fibrosus in 6 of the 10 discs in the $\mathrm{H}$ BMSC group (Figures 6(e) and 6(f)), as well as 2 of the 10 in the BMSC group. The number of BMSC-GFP in the nucleus pulposus region and annulus fibrosus region of the $\mathrm{H}$-BMSC group was much higher compared with that of the BMSC group (Figure $6(\mathrm{~h}), P<0.05)$. These mean that much more BMSC-GFP in H-BMSC group can migrate into annulus fibrosus region, and $\mathrm{HP}$ can upregulate the migration of BMSCs. BMSC-GFP localized in the nucleus pulposus region presented a more rounded shape, similar to the native nucleus pulposus cells (Figures 6(b) and 6(e)). The BMSC-GFP in the inner annulus fibrosus region were spindle-shaped and similar to native annulus fibrosus cells, which may "differentiate" into annulus fibrosus cells (Figures 6(g)-6(i)). From the immunohistochemistry result (supplementary Figure 1), we found that the transplanted BMSCs could express the collagen II and aggrecan. We also found that all of the NP cells and the extracellular matrix in the nucleus pulposus region were stained by immunohistochemistry collagen II and aggrecan, and the transplanted BMSCs surround the positive extracellular matrix. All these dates may lead to the false positive of transplanted BMSCs and need more future study. HP enhanced BMSC survival and migration after transplantation into the degenerated IVD.

3.8. HP Enhanced BMSC Matrix-Associated Protein Expression. Western blot was utilized to analyze the expression of collagen II, aggrecan, and MMP-13 protein in nucleus pulposus tissue after 4 weeks of cell transplantation (Figure 7). Collagen II and aggrecan were significantly decreased in the control, BMSC, and H-BMSC groups, compared with the sham group $(P<0.01)$, 


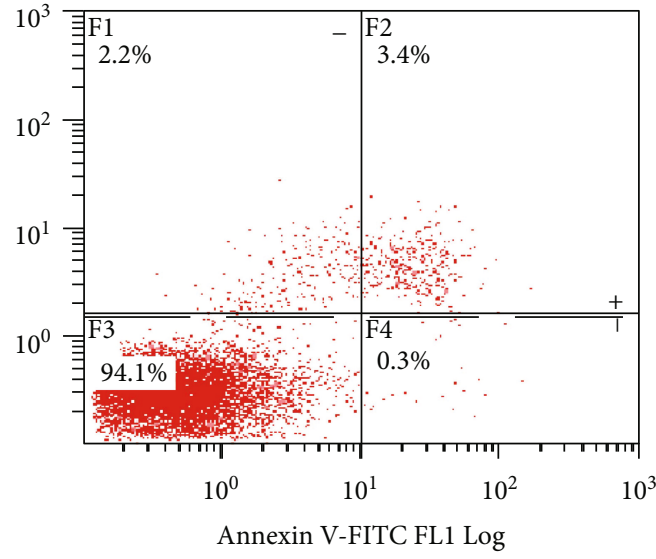

(a)

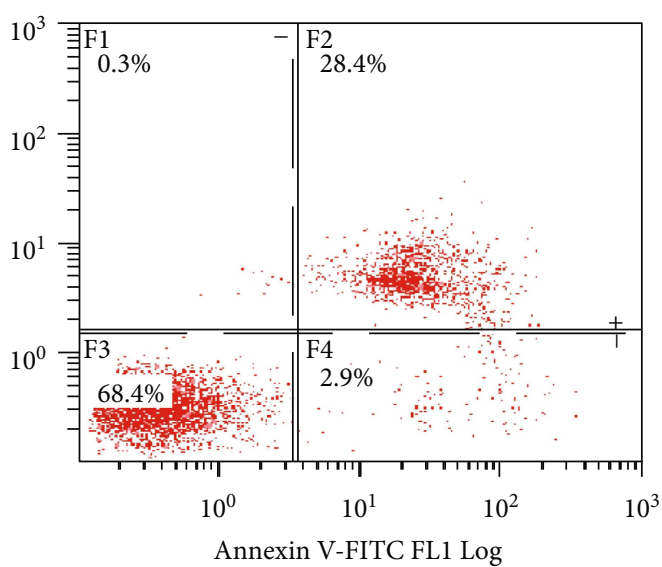

(c)

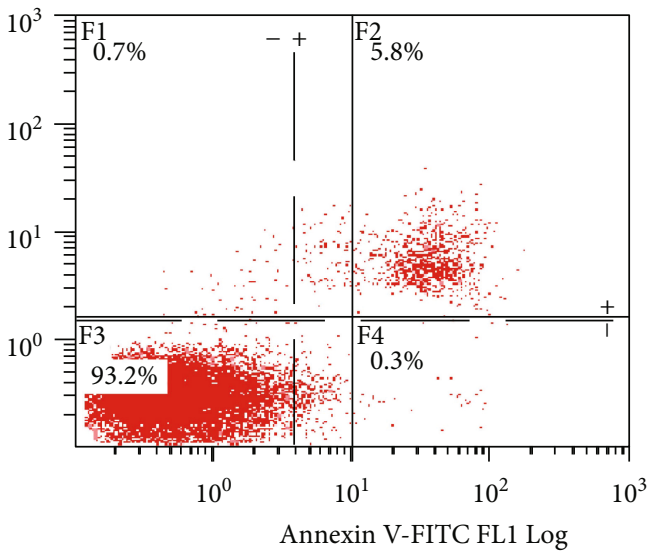

(b)

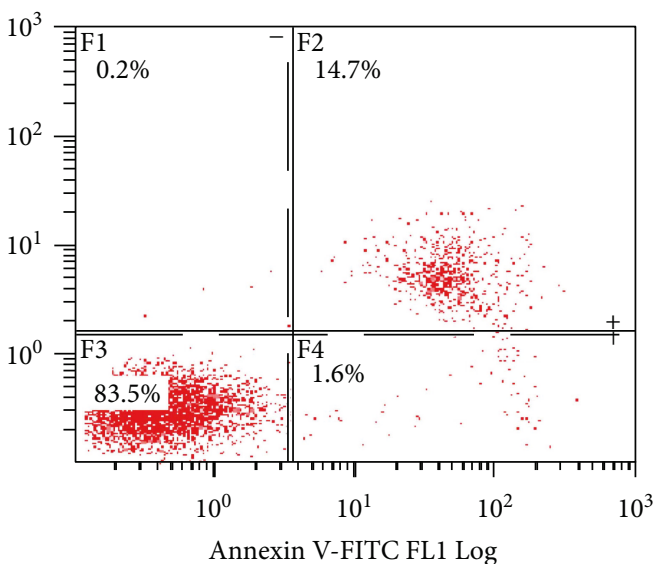

(d)

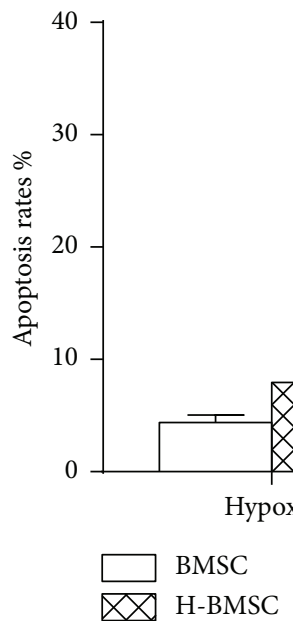

(e)

Figure 2: HP increased BMSC tolerance to serum deprivation. (a-d) show the apoptosis rate of BMSCs detected by FCM. (e) shows the apoptosis rate of BMSCs. Data presented here is the mean \pm SD. ${ }^{*} P<0.05$ versus BMSC group $(n=6)$.

indicating that matrix-associated protein expression was reduced significantly when the IVDs were degenerated. Meanwhile, the protein expression of collagen II and aggrecan in the H-BMSC group was significantly higher than that in the BMSC group $(P<0.05)$. MMP-13 protein expression increased significantly in the control group compared with sham group $(P<0.05)$. In comparison with the BMSC group, the MMP-13 level decreased drastically in the H-BMSC group $(P<0.05)$. All of these results indicated that BMSCs enhanced matrix associated 


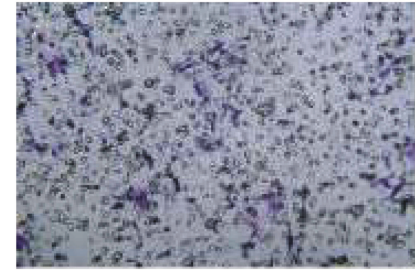

(a)

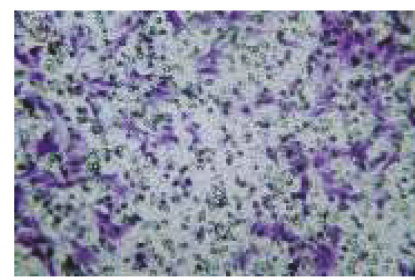

(d)

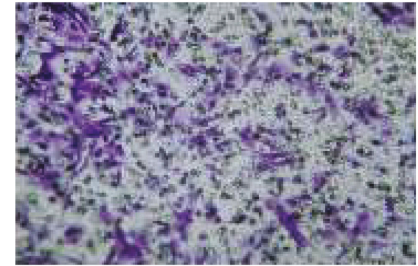

(b)

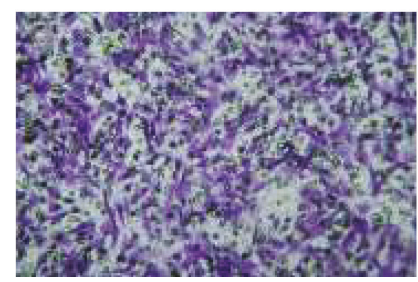

(e)

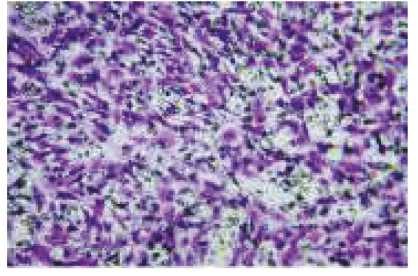

(c)

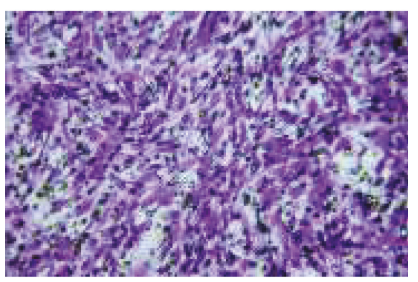

(f)

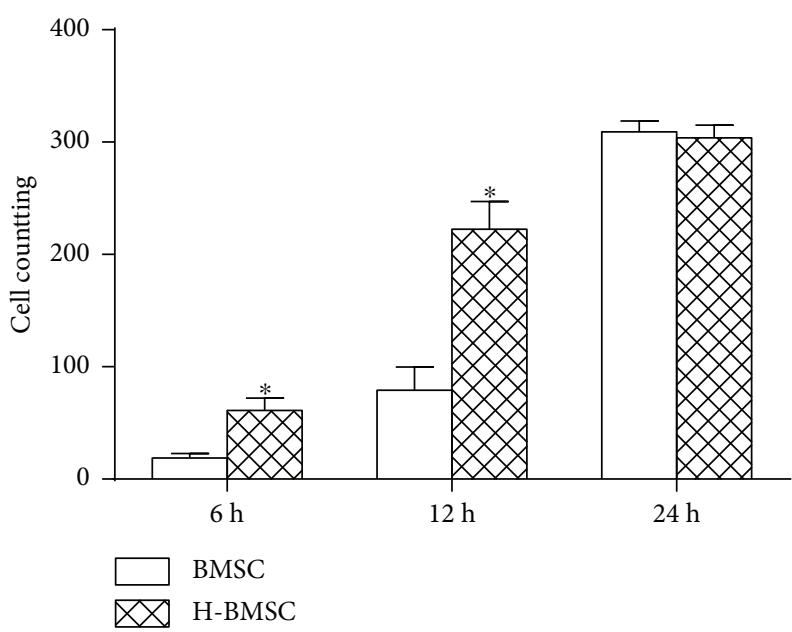

(g)

Figure 3: HP upregulated the migration of BMSCs. (a), (b), and (c) show the number of migrated cells in the BMSC group at 6, 12, and 24 $\mathrm{h}$ $(200 \times) .(d),(e)$, and (f) represent the number of migrated cells in the H-BMSC group at 6 , 12, and $24 \mathrm{~h}(200 \times)$. (g) shows the number of migrated BMSCs in two groups at different times. Data presented here is the mean \pm SD. ${ }^{*} P<0.05$ versus BMSC group ( $n=6$ ).

collagen II and aggrecan protein expression by suppressing the MMP-13 pathway and that HP could upregulate this effect.

\section{Discussion}

The aim of this research was to prove the hypothesis that HP can enhance the capacity of BMSCs to repair DDD by increasing implanted cell survival and migration. Based on the result of BMSC proliferation (Table 2) and apoptosis (Figure 2), pretreatment with $100 \mu \mathrm{M} \mathrm{CoCl}_{2}$ for $24 \mathrm{~h}$ was selected as the HP condition in this experiment. We found that HP could significantly enhance the migration ability of BMSCs via pathways of HIF- $1 \alpha$ and CXCR4 and decrease BMSC apoptosis by the pathways of caspase- 3 and bcl-2 in vitro (Figure 4). The effect of HP on BMSC migration and apoptosis in vitro provided the theoretical basis for using H-BMSCs in the treatment DDD in vivo. To study whether HP could improve the therapeutic effect of BMSCs to IVD degeneration, we assessed the transplanted BMSC survival and migration after 4 weeks (Figure 6), DHI (Figure 5) and matrix-associated protein collagen II, aggrecan, and MMP13 (Figure 7) in IVDs. BMSC transplantation can effectively treat DDD, and this result is consistent with previous studies [8-11]. The HP could enhance the BMSC treatment effect to $\mathrm{DDD}$, which is consistent with the results in vitro. HP can enhance the capacity of BMSCs to repair DDD by increasing implanted cell survival and migration.

IVD degeneration is an inevitable consequence of aging and disc pressure, and its associated problems such as low back pain are severe health problems with a large socioeconomic burden [39]. Cell therapy is a new hopeful therapy for this disease [40, 41]. Various kinds of mesenchymal stem cells have been used to repair the DDD and achieve good results, such as the cells from the bone marrow [8-11], fat [42], umbilical cord blood [43], Wharton's jelly [44], olfactory stem cells [45], and induced pluripotent stem cells [46]. BMSCs received widespread attention for its easy to obtain, pluripotent, and multipotent abilities [8-11]. The research about the comparisons between the stem cells and 


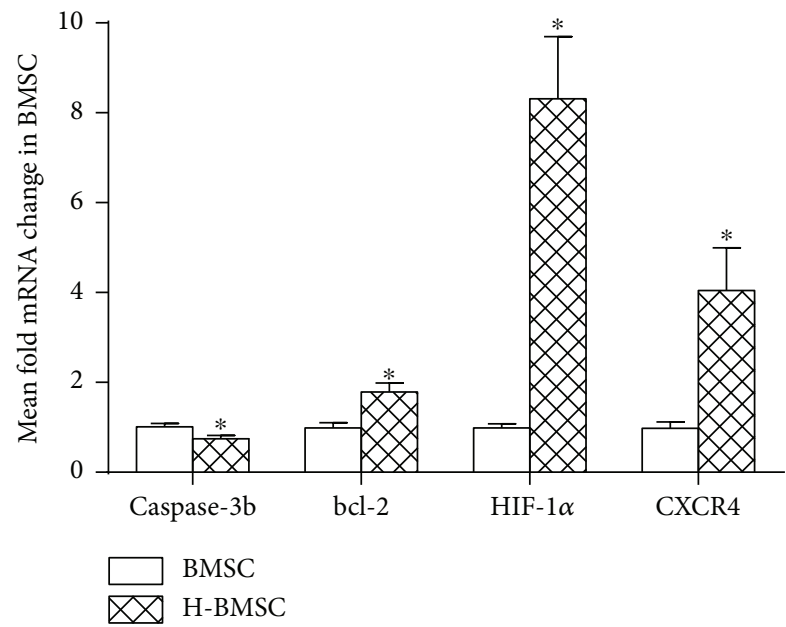

Figure 4: HP enhances BMSC migration via HIF- $1 \alpha$ and CXCR4 pathways and tolerance to serum deprivation by regulating bcl-2 and caspase-3. Data presented here is the mean \pm SD. ${ }^{*} P<0.05$ versus BMSC group $(n=6)$.

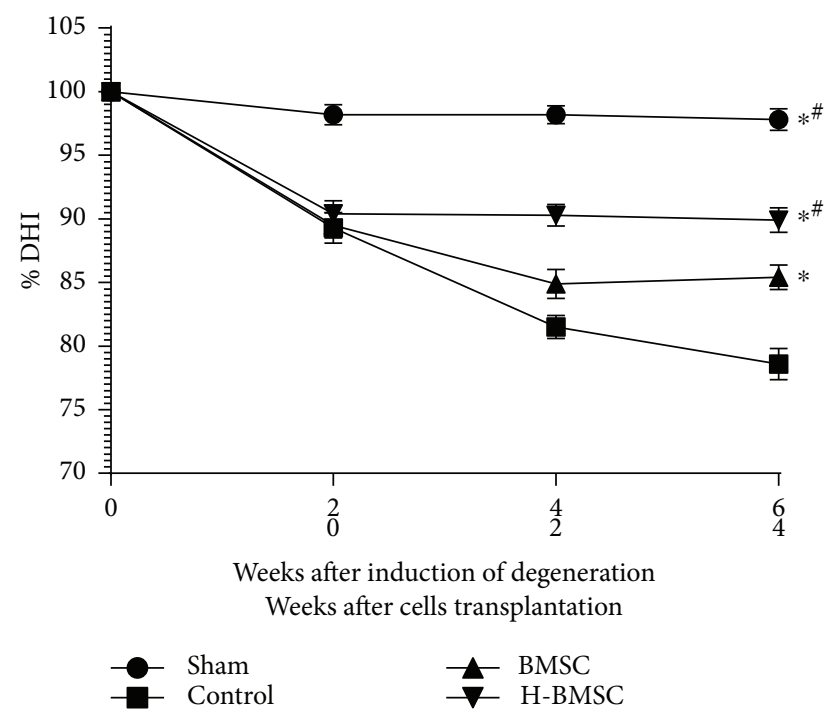

Figure 5: Change of the DHI at different time points after cell transplantation. Data presented here is the mean \pm SEM. ${ }^{*} P<0.05$ versus control group, ${ }^{\#} P<0.05$ versus BMSC group $(n=10)$.

differentiated cells to treat the DDD is limited and controversial, which needs future research. The differentiated cells may be superior in producing more ECM and be inferior in antidamage ability [47, 48]. However, there are many barriers that need to be solved in cell therapy. Injection into IVDs will speed up degeneration of IVDs. In the process of cell transplantation, it is necessary to use a needle to penetrate the fibrous rings and enter into the nucleus pulposus, which leads to destruction of the structural integrity of IVDs. Carragee's study confirmed that IVD degeneration significantly accelerated in patients who had undergone discography [49]. Vadala et al. found that BMSCs may leak out of the nucleus and occur undesirable osteophyte [50]. To minimize these complications, a 33-gauge microinjector was used and cell transplantation for each IVD was at least $5 \mathrm{~min}$ in this study. On one hand, the minimal needle was used to reduce disc degeneration caused by the cell transplantation itself; on the other hand, the injection time was at least $5 \mathrm{~min}$ to reduce cell leakage. A key barrier restricting cell transplantation application in DDD treatment is the special hypertonic and hypoxic environment in IVDs. The implanted cells may suffer from overt cell loss, cell activity, and differentiation decreased in this harsh, nutrient-poor environment $[51,52]$. The application of HP for transplanted stem cell therapies has been reported for many diseases in recent years, such as infarcted heart [26] and ischemic stroke [27, 53]. Considering the special IVD environment with biomechanical stress and hypoxia, we demonstrated that HP could significantly enhance the capacity of BMSCs to repair DDD and provided an effective way to solve the overt cell loss, cell activity, and differentiation decreased in the cell transplantation of DDD treatment.

It is controversial how to accurately determine the BMSC differentiated into NP- or AF-like cells in vivo so far. There are only limited direct researches about the cell differentiation in the IVD in the published paper from PubMed [8-11]. In these papers, there were no standard and exact indicators to determine the differentiation of BMSCs into IVD. To study the differentiation of transplanted BMSCs into IVD tissue, we had tried to use immunohistochemistry to detect the expression of GFP, collagen II, and aggrecan in transplanted BMSCs by using antibody collagen II and anti-rat aggrecan (Supplementary Fig. 1). From the immunohistochemistry result, we found that the transplanted BMSCs could express the collagen II and aggrecan. We also found that all of the NP cells and the extracellular matrix in the nucleus pulposus region were stained by immunohistochemistry collagen II and aggrecan, and the transplanted BMSCs surround the positive extracellular matrix. All these dates may lead to the false positive of transplanted BMSCs. The research about the differentiation of BMSCs into IVD cell/tissue needs standard and exact indicator, which is a direction of our future research.

$\mathrm{CoCl}_{2}$ is a classical chemical hypoxia simulator and widely used because of the advantages of simple use and easy, precise control of treatment conditions [54-56]. The mechanism of its hypoxia simulation is the replacement of $\mathrm{Fe}^{2+}$ by $\mathrm{Co}^{2+}$ in hemoglobin, changing hemoglobin to a deoxidized state. In this state, the cells "feel" hypoxic in a normoxic environment [57]. It is easy to control the experimental conditions with $\mathrm{CoCl}_{2}$ in vitro, though there are some limitations. There is no evidence about the role of $\mathrm{CoCl}_{2}$ accumulation in cells. Therefore, we repeatedly washed with normal culture medium to minimize the influence of residual $\mathrm{CoCl}_{2}$ in the culture medium. The mechanism of $\mathrm{CoCl}_{2}$ is that $\mathrm{Co}^{2+}$ increases the expression of HIF and CXCR4 [26-28, 58-60]. CXCR4 is considered a key factor in migration of BMSCs [61]. Cell culture conditions could decrease the migration ability of BMSCs via downregulating the CXCR4 expression [62]. The fresh isolated BMSCs can migrate to the damaged tissue, while the migration ability will decrease significantly after BMSC culture 


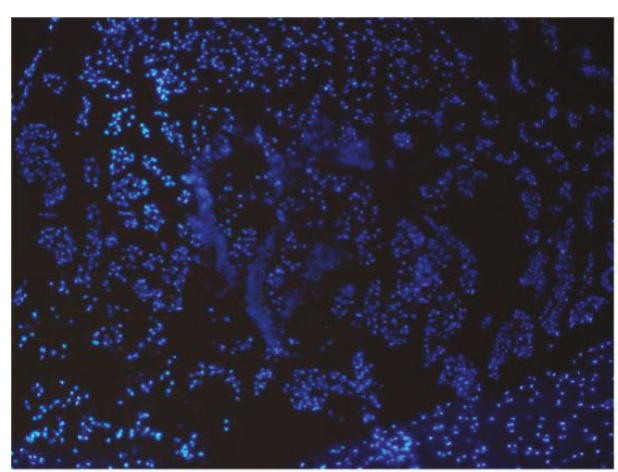

(a)

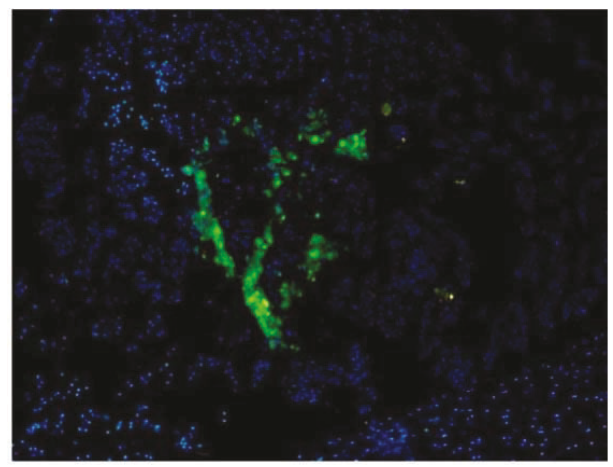

(c)

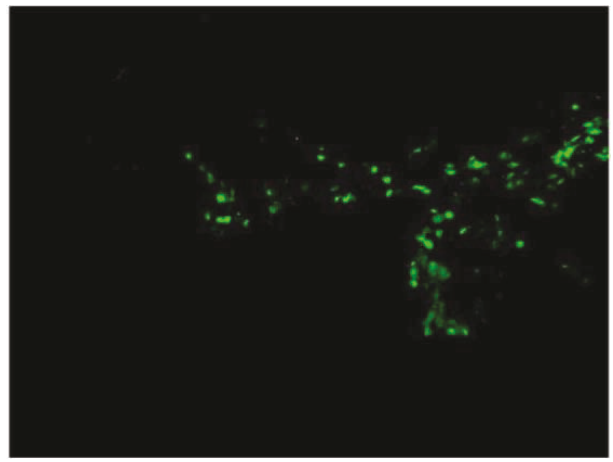

(e)

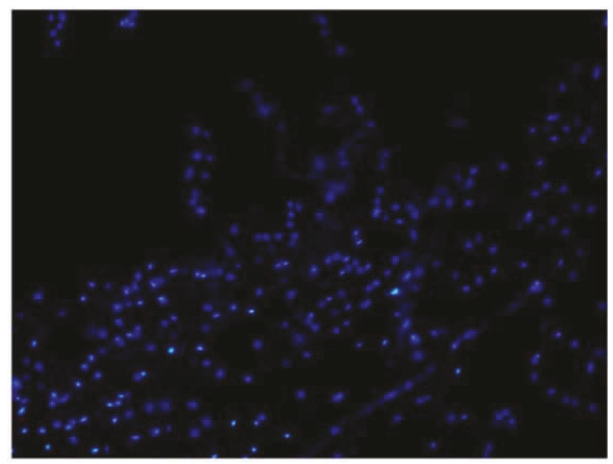

(g)

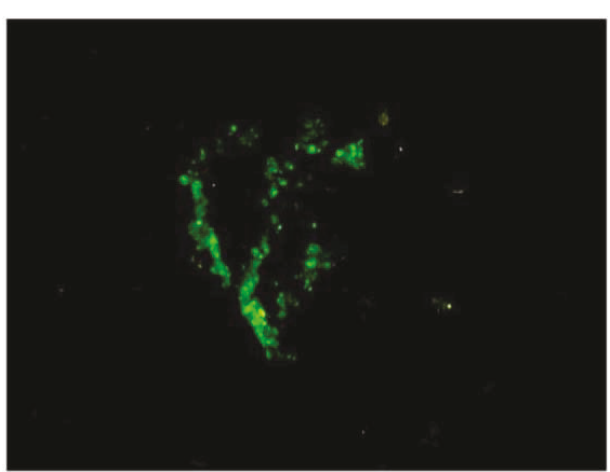

(b)

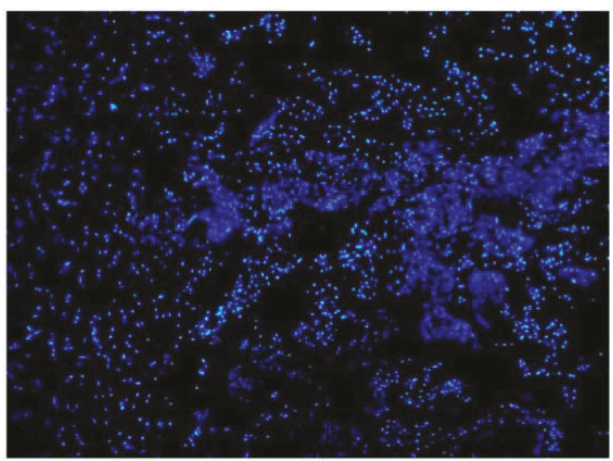

(d)

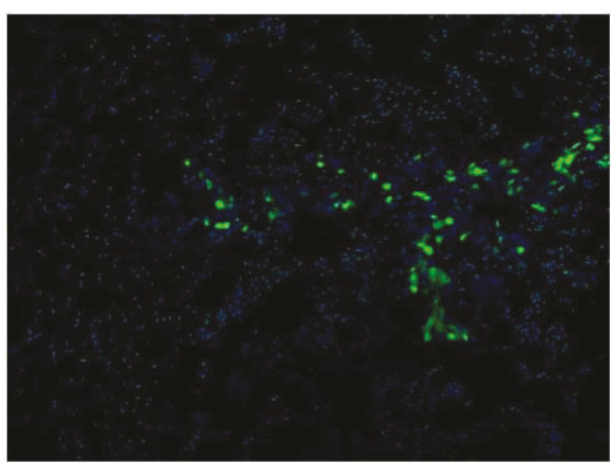

(f)

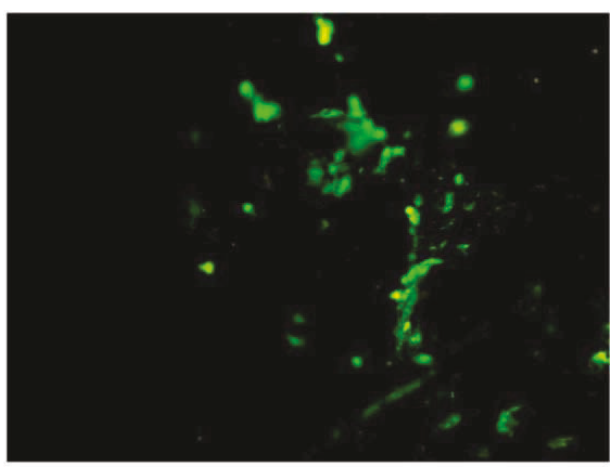

(h)

FIGURe 6: Continued. 


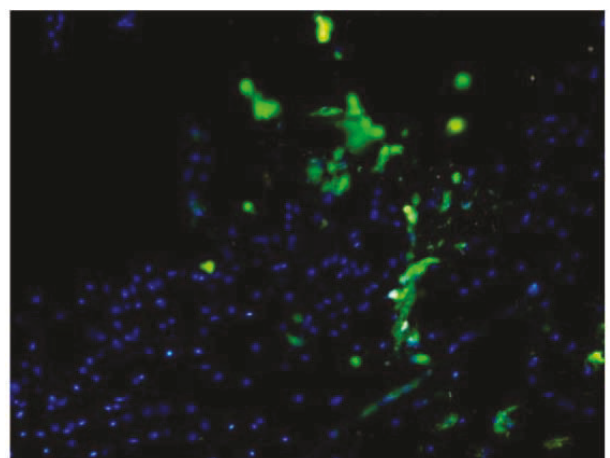

(i)

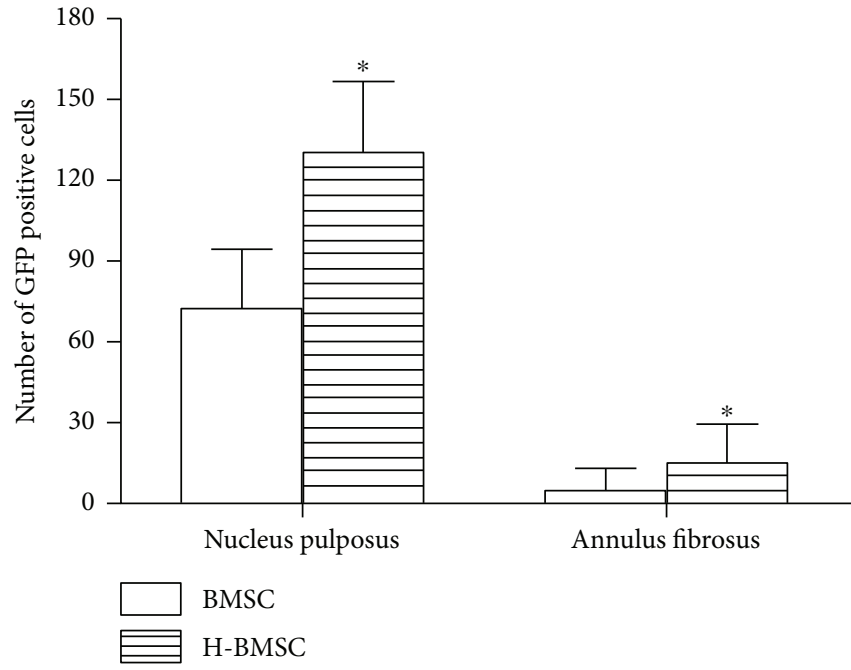

(j)

Figure 6: The survival and migration of BMSCs 4 weeks after cell transplantation. (a-c) show the BMSC group, (d-i) show the H-BMSC group. (a), (d), and (g) show the cell nucleus image stained by DAPI. (b), (e), and (h) show GFP-positive cells. (c) Merges of (a) and (b) $(100 \times)$. (f) Merges of $(d)$ and $(e)(100 \times)$. (i) Merges of $(g)$ and $(h)(400 \times)$. (j) shows the number of BMSC-GFP in the nucleus pulposus and annulus fibrosus regions. Data presented here is the mean \pm SD. ${ }^{*} P<0.05$ versus BMSC group $(n=10)$.
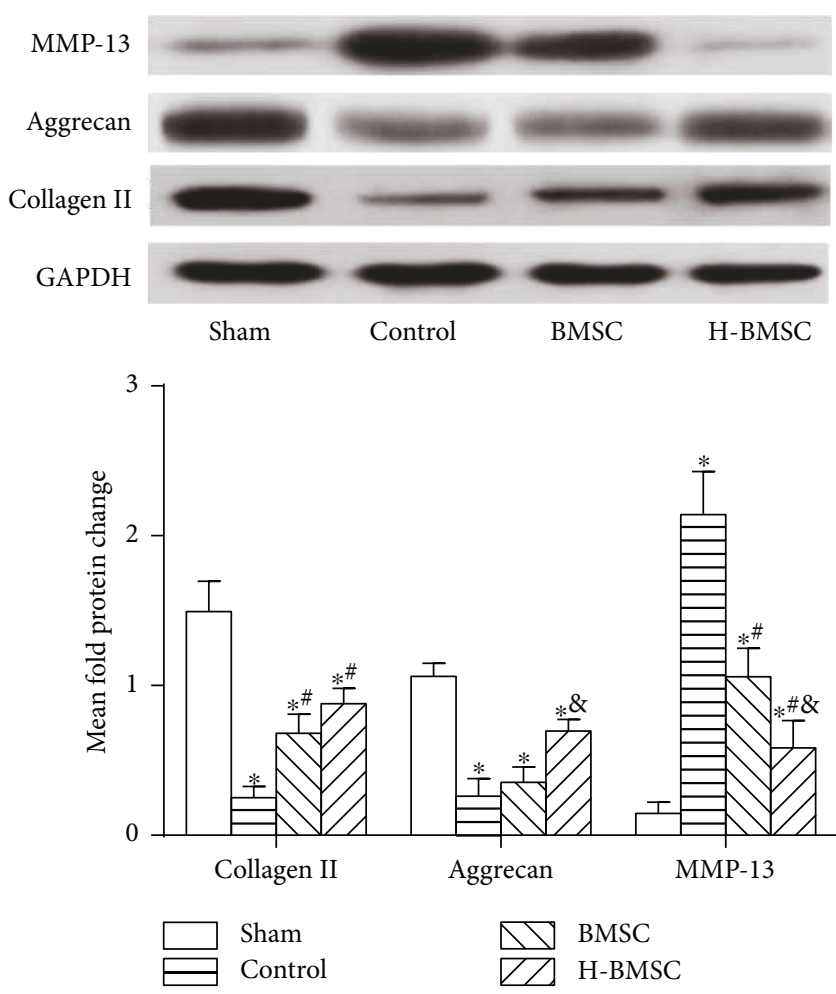

Figure 7: HP enhanced BMSC matrix-associated protein expression $(n=6)$. Data presented here is the mean $\pm \mathrm{SD} .{ }^{*} P<$ 0.05 versus sham group; ${ }^{\#} P<0.05$ versus control group; ${ }^{\&} P<0.05$ versus BMSC group $(n=5)$.

in vitro after $24 \mathrm{~h}$. HP could promote the migration of BMSCs that have been demonstrated in some researches [63-67]. In this study, we confirmed that HP induced by $\mathrm{CoCl}_{2}$ could promote migration, homing, and colonization of BMSCs via the pathway of CXCR4 and HIF-1 in vitro.

The optimal HP condition should have a slight effect on cell viability and improve migration and cell tolerance to damage significantly. Therefore, according to the results of the cell proliferation and apoptosis, $100 \mu \mathrm{M} \mathrm{CoCl}_{2}$ cultured for $24 \mathrm{~h}$ was selected. The effects of $\mathrm{CoCl}_{2}$ were concentration dependent [60]. Long-term cell culture time may lead to cell differentiation, senescence, and other problems [68, 69]. Hypoxia may lead to differentiation of BMSCs [70] and affect cell activity and function via pathways of HIF [71, 72]. It may be more appropriate to select a higher concentration of $\mathrm{CoCl}_{2}$ for a shorter culture time, without significantly reducing cell activity and increasing apoptosis. HP can lead to the adaptability change in BMSCs. Although the mechanism was unclear, the adaptability change in BMSCs can produce stronger adaptability and resistance to the subsequent strong and harmful stimulation. HP can promote BMSC migration via the HIF- $1 \alpha$ and $\mathrm{CXCR} 4$ pathways and decrease apoptosis by way of caspase- 3 and bcl-2, which was confirmed in this study.

\section{Conclusion}

In conclusion, transplantation of $\mathrm{H}$-BMSC retards IVD degeneration via enhancing implanted cell survival and migration in rats, which provides an effective way to improve the effects of BMSC transplantation in DDD treatment. However, the environment and degenerate model of IVD are different between rats and humans. Further studies should be performed about H-BMSC transplantation in clinical applications. 


\section{Conflicts of Interest}

The authors declare no competing financial interests.

\section{Authors' Contributions}

Weiheng Wang and Guoying Deng performed the experimental work. Yang Wang wrote the manuscript. Yang Wang, Jun $\mathrm{Ma}$, and Xiaodong Huang helped in methods and analysis. Xiaojian Ye, Jiangming $\mathrm{Yu}$, and Yanhai Xi designed and supported the experiments. All authors reviewed and approved the manuscript. Weiheng Wang, Yang Wang, and Guoying Deng contributed equally to this work. Jiangming $\mathrm{Yu}$, Yanhai Xi, and Xiaojian Ye supported this work equally.

\section{Acknowledgments}

This work supported by National Natural Science Foundation of China (Grant no. 81472071 and Grant no. 81301537) and Perioperative Blood Management of Shanghai (Grant no. 2016-N-14-06).

\section{Supplementary Materials}

Supplementary Figure 1: differentiation of BMSCs into IVD 4 weeks after transplantation $(200 \times)$. A and E represent the cell nucleus image overlaid by DAPI. B and F show GFP-positive BMSCs. C shows collagen II-positive cells. G shows aggrecan-positive cells. D merging of A, B, and C. H merging of E, F, and G. (Supplementary Materials)

\section{References}

[1] N. Bogduk, C. Aprill, and R. Derby, "Lumbar discogenic pain: state-of-the-art review," Pain Medicine, vol. 14, no. 6, pp. 813836, 2013.

[2] P. Wilkens, I. B. Scheel, O. Grundnes, C. Hellum, and K. Storheim, "Prognostic factors of prolonged disability in patients with chronic low back pain and lumbar degeneration in primary care: a cohort study," Spine, vol. 38, no. 1, pp. 6574, 2013.

[3] A. Bhattacharya and J. P. Leigh, "Musculoskeletal disorder costs and medical claim filing in the US retail trade sector," Industrial Health, vol. 49, no. 4, pp. 517-522, 2011.

[4] P. P. Raj, "Intervertebral disc: anatomy-physiology-pathophysiology-treatment," Pain Practice, vol. 8, no. 1, pp. 18-44, 2008.

[5] F. Ding, Z. W. Shao, and L. M. Xiong, "Cell death in intervertebral disc degeneration," Apoptosis, vol. 18, no. 7, pp. 777785, 2013.

[6] S. J. Lipson and H. Muir, "1980 Volvo award in basic science. Proteoglycans in experimental intervertebral disc degeneration," Spine, vol. 6, no. 3, pp. 194-210, 1981.

[7] W. Tong, Z. Lu, L. Qin et al., "Cell therapy for the degenerating intervertebral disc," Translational Research, vol. 181, pp. 49$58,2017$.

[8] S. Illien-Junger, G. Pattappa, M. Peroglio et al., "Homing of mesenchymal stem cells in induced degenerative intervertebral discs in a whole organ culture system," Spine, vol. 37, no. 22, pp. 1865-1873, 2012.
[9] E. Y. See, S. L. Toh, and J. C. Goh, "Simulated intervertebral disc-like assembly using bone marrow-derived mesenchymal stem cell sheets and silk scaffolds for annulus fibrosus regeneration," Journal of Tissue Engineering and Regenerative Medicine, vol. 6, no. 7, pp. 528-535, 2012.

[10] Z. Yi, T. Guanjun, C. Lin, and P. Zifeng, "Effects of transplantation of hTIMP-1-expressing bone marrow mesenchymal stem cells on the extracellular matrix of degenerative intervertebral discs in an in vivo rabbit model," Spine, vol. 39, no. 11, pp. E669-E675, 2014.

[11] J. Zhu, H. Tang, Z. Zhang et al., "Kaempferol slows intervertebral disc degeneration by modifying LPS-induced osteogenesis/adipogenesis imbalance and inflammation response in BMSCs," International Immunopharmacology, vol. 43, pp. 236-242, 2017.

[12] V. Sivakamasundari and T. Lufkin, "Stemming the degeneration: IVD stem cells and stem cell regenerative therapy for degenerative disc disease," Advances in Stem Cells, vol. 2013, article 724547, 22 pages, 2013.

[13] S. M. Richardson, N. Hughes, J. A. Hunt, A. J. Freemont, and J. A. Hoyland, "Human mesenchymal stem cell differentiation to NP-like cells in chitosan-glycerophosphate hydrogels," Biomaterials, vol. 29, no. 1, pp. 85-93, 2008.

[14] C. Cao, J. Zou, X. Liu et al., "Bone marrow mesenchymal stem cells slow intervertebral disc degeneration through the NF- $\kappa \mathrm{B}$ pathway," The Spine Journal, vol. 15, no. 3, pp. 530-538, 2015.

[15] V. Y. Leung, D. M. Aladin, F. Lv et al., "Mesenchymal stem cells reduce intervertebral disc fibrosis and facilitate repair," Stem Cells, vol. 32, no. 8, pp. 2164-2177, 2014.

[16] C. J. Ma, X. Liu, L. Che, Z. H. Liu, D. Samartzis, and H. Q. Wang, "Stem cell therapies for intervertebral disc degeneration: immune privilege reinforcement by Fas/FasL regulating machinery," Current Stem Cell Research \& Therapy, vol. 10, no. 4, pp. 285-295, 2015.

[17] T. Grunhagen, G. Wilde, D. M. Soukane, S. A. Shirazi-Adl, and J. P. Urban, "Nutrient supply and intervertebral disc metabolism," The Journal of Bone and Joint Surgery-American Volume, vol. 88, Supplement 2, pp. 30-35, 2006.

[18] A. Nachemson, T. Lewin, A. Maroudas, and M. A. Freeman, "In vitro diffusion of dye through the end-plates and the annulus fibrosus of human lumbar inter-vertebral discs," Acta Orthopaedica Scandinavica, vol. 41, no. 6, pp. 589-607, 1970.

[19] J. P. Urban and J. F. Mcmullin, "Swelling pressure of the inervertebral disc: influence of proteoglycan and collagen contents," Biorheology, vol. 22, no. 2, pp. 145-157, 1985.

[20] E. M. Bartels, J. C. Fairbank, C. P. Winlove, and J. P. Urban, "Oxygen and lactate concentrations measured in vivo in the intervertebral discs of patients with scoliosis and back pain," Spine, vol. 23, no. 1, pp. 1-7, 1998.

[21] H. Ishihara, K. Warensjo, S. Roberts, and J. P. Urban, "Proteoglycan synthesis in the intervertebral disk nucleus: the role of extracellular osmolality," American Journal of Physiology-Cell Physiology, vol. 272, no. 5, pp. C1499-C1506, 1997.

[22] B. Van Dijk, E. Potier, and K. Ito, "Culturing bovine nucleus pulposus explants by balancing medium osmolarity," Tissue Engineering Part C: Methods, vol. 17, no. 11, pp. 1089-1096, 2011.

[23] B. S. Buchmaier, A. Bibi, G. A. Muller et al., "Renal cells express different forms of vimentin: the independent expression alteration of these forms is important in cell resistance 
to osmotic stress and apoptosis," PLoS One, vol. 8, no. 7, article e68301, 2013.

[24] C. Li, Z. Guo, B. Guo, Y. Xie, J. Yang, and A. Wang, "Inhibition of the endogenous $\mathrm{CSE} / \mathrm{H}_{2} \mathrm{~S}$ system contributes to hypoxia and serum deprivation-induced apoptosis in mesenchymal stem cells," Molecular Medicine Reports, vol. 9, no. 6, pp. 2467-2472, 2014.

[25] J. Torras, I. Herrero-Fresneda, N. Lloberas, M. Riera, J. Ma Cruzado, and J. Ma Grinyo, "Promising effects of ischemic preconditioning in renal transplantation," Kidney International, vol. 61, no. 6, pp. 2218-2227, 2002.

[26] X. Hu, S. P. Yu, J. L. Fraser et al., “Transplantation of hypoxiapreconditioned mesenchymal stem cells improves infarcted heart function via enhanced survival of implanted cells and angiogenesis," The Journal of Thoracic and Cardiovascular Surgery, vol. 135, no. 4, pp. 799-808, 2008.

[27] M. H. Theus, L. Wei, L. Cui et al., "In vitro hypoxic preconditioning of embryonic stem cells as a strategy of promoting cell survival and functional benefits after transplantation into the ischemic rat brain," Experimental Neurology, vol. 210, no. 2no. 2, pp. 656-670, 2008.

[28] L. Wei, J. L. Fraser, Z. Y. Lu, X. Hu, and S. P. Yu, “Transplantation of hypoxia preconditioned bone marrow mesenchymal stem cells enhances angiogenesis and neurogenesis after cerebral ischemia in rats," Neurobiology of Disease, vol. 46, no. 3, pp. 635-645, 2012.

[29] G. H. Danet, Y. Pan, J. L. Luongo, D. A. Bonnet, and M. C. Simon, "Expansion of human SCID-repopulating cells under hypoxic conditions," The Journal of Clinical Investigation, vol. 112, no. 1, pp. 126-135, 2003.

[30] M. Lotfinia, S. Lak, N. Mohammadi Ghahhari et al., "Hypoxia pre-conditioned embryonic mesenchymal stem cell secretome reduces IL-10 production by peripheral blood mononuclear cells," Iranian Biomedical Journal, vol. 21, no. 1, pp. 24-31, 2017.

[31] L. L. Yuan and Y. J. Guan, "Optimal concentration and time window for proliferation and differentiation of neural stem cells from embryonic cerebral cortex: 5\% oxygen preconditioning for 72 hours," Neural Regeneration Research, vol. 10, no. 9, pp. 1516-1522, 2015.

[32] K. Fynes, R. Tostoes, L. Ruban, B. Weil, C. Mason, and F. S. Veraitch, "The differential effects of $2 \%$ oxygen preconditioning on the subsequent differentiation of mouse and human pluripotent stem cells," Stem Cells and Development, vol. 23, no. 16, pp. 1910-1922, 2014.

[33] P. C. Hughes and J. M. Tanner, "The assessment of skeletal maturity in the growing rat," Journal of Anatomy, vol. 106, Part 2, pp. 371-402, 1970.

[34] M. A. Rousseau, J. A. Ulrich, E. C. Bass, A. G. Rodriguez, J. J. Liu, and J. C. Lotz, "Stab incision for inducing intervertebral disc degeneration in the rat," Spine, vol. 32, no. 1, pp. 17-24, 2007.

[35] G. Deng, W. Wang, C. Yang, R. Gao, X. Yang, and X. Ye, "Shaking improves the whole bone marrow adherent method of purification," Molecular Medicine Reports, vol. 13, no. 4, pp. 3133-3138, 2016.

[36] Y. Lin, F. Li, W. Chen, H. Zeng, A. Chen, and W. Xiong, "Single-level lumbar pyogenic spondylodiscitis treated with miniopen anterior debridement and fusion in combination with posterior percutaneous fixation via a modified anterior lumbar interbody fusion approach," Journal of Neurosurgery Spine, vol. 23, no. 6, pp. 747-753, 2015.
[37] M. Okabe, M. Ikawa, K. Kominami, T. Nakanishi, and Y. Nishimune, "Green mice' as a source of ubiquitous green cells,” FEBS Letters, vol. 407, no. 3, pp. 313-319, 1997.

[38] Q. Tan, P. P. Lui, Y. F. Rui, and Y. M. Wong, "Comparison of potentials of stem cells isolated from tendon and bone marrow for musculoskeletal tissue engineering," Tissue Engineering Part A, vol. 18, no. 7-8, pp. 840-851, 2012.

[39] V. Goz, J. H. Weinreb, F. Schwab, V. Lafage, and T. J. Errico, "Comparison of complications, costs, and length of stay of three different lumbar interbody fusion techniques: an analysis of the Nationwide Inpatient Sample database," The Spine Journal, vol. 14, no. 9, pp. 2019-2027, 2014.

[40] J. Dowdell, M. Erwin, T. Choma, A. Vaccaro, J. Iatridis, and S. K. Cho, "Intervertebral disk degeneration and repair," Neurosurgery, vol. 80, no. 3S, pp. S46-S54, 2017.

[41] F. Wang, R. Shi, F. Cai, Y. T. Wang, and X. T. Wu, "Stem cell approaches to intervertebral disc regeneration: obstacles from the disc microenvironment," Stem Cells and Development, vol. 24, no. 21, pp. 2479-2495, 2015.

[42] T. Ganey, W. C. Hutton, T. Moseley, M. Hedrick, and H. J. Meisel, "Intervertebral disc repair using adipose tissuederived stem and regenerative cells: experiments in a canine model," Spine, vol. 34, no. 21, pp. 2297-2304, 2009.

[43] D. G. Anderson, D. Markova, H. S. An et al., "Human umbilical cord blood-derived mesenchymal stem cells in the cultured rabbit intervertebral disc: a novel cell source for disc repair," American Journal of Physical Medicine \& Rehabilitation, vol. 92, no. 5, pp. 420-429, 2013.

[44] S. K. Leckie, G. A. Sowa, B. P. Bechara et al., "Injection of human umbilical tissue-derived cells into the nucleus pulposus alters the course of intervertebral disc degeneration in vivo," The Spine Journal, vol. 13, no. 3, pp. 263-272, 2013.

[45] W. Murrell, E. Sanford, L. Anderberg, B. Cavanagh, and A. Mackay-Sim, "Olfactory stem cells can be induced to express chondrogenic phenotype in a rat intervertebral disc injury model," The Spine Journal, vol. 9, no. 7, pp. 585-594, 2009.

[46] J. Chen, E. J. Lee, L. Jing, N. Christoforou, K. W. Leong, and L. A. Setton, "Differentiation of mouse induced pluripotent stem cells (iPSCs) into nucleus pulposus-like cells in vitro," PLoS One, vol. 8, no. 9, article e75548, 2013.

[47] F. L. Acosta Jr., L. Metz, H. D. Adkisson et al., "Porcine intervertebral disc repair using allogeneic juvenile articular chondrocytes or mesenchymal stem cells," Tissue Engineering Part A, vol. 17, no. 23-24, pp. 3045-3055, 2011.

[48] A. A. Allon, N. Aurouer, B. B. Yoo, E. C. Liebenberg, Z. Buser, and J. C. Lotz, "Structured coculture of stem cells and disc cells prevent disc degeneration in a rat model," The Spine Journal, vol. 10, no. 12, pp. 1089-1097, 2010.

[49] J. M. Cuellar, M. P. Stauff, R. J. Herzog, J. A. Carrino, G. A. Baker, and E. J. Carragee, "Does provocative discography cause clinically important injury to the lumbar intervertebral disc? A 10-year matched cohort study," The Spine Journal, vol. 16, no. 3, pp. 273-280, 2016.

[50] G. Vadala, G. Sowa, M. Hubert, L. G. Gilbertson, V. Denaro, and J. D. Kang, "Mesenchymal stem cells injection in degenerated intervertebral disc: cell leakage may induce osteophyte formation," Journal of Tissue Engineering and Regenerative Medicine, vol. 6, no. 5, pp. 348-355, 2012.

[51] K. Wuertz, K. Godburn, C. Neidlinger-Wilke, J. Urban, and J. C. Iatridis, "Behavior of mesenchymal stem cells in the 
chemical microenvironment of the intervertebral disc," Spine, vol. 33, no. 17, pp. 1843-1849, 2008.

[52] E. Potier, E. Ferreira, A. Meunier, L. Sedel, D. LogeartAvramoglou, and H. Petite, "Prolonged hypoxia concomitant with serum deprivation induces massive human mesenchymal stem cell death," Tissue Engineering, vol. 13, no. 6, pp. 1325-1331, 2007.

[53] J. Chen, Y. Yang, L. Shen et al., "Hypoxic preconditioning augments the therapeutic efficacy of bone marrow stromal cells in a rat ischemic stroke model," Cellular and Molecular Neurobiology, vol. 37, no. 6, pp. 1115-1129, 2017.

[54] Y. Lu, W. Chen, C. Lin et al., "The protective effects of propofol against $\mathrm{CoCl}_{2}$-induced $\mathrm{HT} 22$ cell hypoxia injury via PP2A/CAMKII $\alpha /$ nNOS pathway," BMC Anesthesiology, vol. 17, no. 1, p. 32, 2017.

[55] M. L. Pinzon-Daza, Y. Cuellar-Saenz, F. Nualart et al., "Oxidative stress promotes doxorubicin-induced Pgp and BCRP expression in colon cancer cells under hypoxic conditions," Journal of Cellular Biochemistry, vol. 118, no. 7, pp. 18681878, 2017.

[56] Y. J. Kim, S. J. Park, N. R. Kim, and H. S. Chin, "Effects of histone deacetylase inhibitor (valproic acid) on the expression of hypoxia-inducible factor-1 alpha in human retinal muller cells," Korean Journal of Ophthalmology, vol. 31, no. 1, pp. 80-85, 2017.

[57] H. Zhu and H. F. Bunn, "Oxygen sensing and signaling: impact on the regulation of physiologically important genes," Respiration Physiology, vol. 115, no. 2, pp. 239-247, 1999.

[58] A. Rani and S. Prasad, " $\mathrm{CoCl}_{2}$-induced biochemical hypoxia down regulates activities and expression of super oxide dismutase and catalase in cerebral cortex of mice," Neurochemical Research, vol. 39, no. 9, pp. 1787-1796, 2014.

[59] P. T. Schumacker, "Hypoxia-inducible factor-1 (HIF-1)," Critical Care Medicine, vol. 33, Supplement 12, pp. S423-S425, 2005.

[60] W. M. Bernhardt, V. Campean, S. Kany et al., "Preconditional activation of hypoxia-inducible factors ameliorates ischemic acute renal failure," Journal of the American Society of Nephrology, vol. 17, no. 7, pp. 1970-1978, 2006.

[61] D. E. Wright, E. P. Bowman, A. J. Wagers, E. C. Butcher, and I. L. Weissman, "Hematopoietic stem cells are uniquely selective in their migratory response to chemokines," Journal of Experimental Medicine, vol. 195, no. 9, pp. 1145-1154, 2002.

[62] M. Honczarenko, Y. Le, M. Swierkowski, I. Ghiran, A. M. Glodek, and L. E. Silberstein, "Human bone marrow stromal cells express a distinct set of biologically functional chemokine receptors," Stem Cells, vol. 24, no. 4, pp. 1030-1041, 2006.

[63] N. Wei, S. P. Yu, X. Gu et al., "Delayed intranasal delivery of hypoxic-preconditioned bone marrow mesenchymal stem cells enhanced cell homing and therapeutic benefits after ischemic stroke in mice," Cell Transplantation, vol. 22, no. 6, pp. 977-991, 2013.

[64] H. Liu, X. F. Yu, J. Teng, J. Z. Zou, Y. Fang, and X. Q. Ding, "Effects of hypoxic preconditioning on the migration of bone marrow derived mesenchymal stem cells," Zhonghua Yi Xue Za Zhi, vol. 92, no. 10, pp. 709-713, 2012.

[65] X. Hu, L. Wei, T. M. Taylor et al., "Hypoxic preconditioning enhances bone marrow mesenchymal stem cell migration via Kv2.1 channel and FAK activation," American Journal of Physiology Cell Physiology, vol. 301, no. 2, pp. C362-C372, 2011.
[66] S. Kim, A. Chaudhry, I. Lee, and J. A. Frank, "Effects of longterm hypoxia and pro-survival cocktail in bone marrowderived stromal cell survival," Stem Cells and Development, vol. 23, no. 5, pp. 530-540, 2014.

[67] J. A. Brown, T. Santra, P. Owens, A. M. Morrison, and F. Barry, "Primary cilium-associated genes mediate bone marrow stromal cell response to hypoxia," Stem Cell Research, vol. 13, no. 2, pp. 284-299, 2014.

[68] A. R. Derubeis and R. Cancedda, "Bone marrow stromal cells (BMSCs) in bone engineering: limitations and recent advances," Annals of Biomedical Engineering, vol. 32, no. 1, pp. 160-165, 2004.

[69] H. Saeed and M. Iqtedar, "Bone marrow stromal cell (BMSC) and skeletal aging: role of telomerase enzyme," Pakistan Journal of Pharmaceutical Sciences, vol. 27, no. 2, pp. 321-333, 2014.

[70] R. Madonna, A. Gorbe, P. Ferdinandy, and R. De Caterina, "Glucose metabolism, hyperosmotic stress, and reprogramming of somatic cells," Molecular Biotechnology, vol. 55, no. 2, pp. 169-178, 2013.

[71] B. Brune and J. Zhou, "The role of nitric oxide (NO) in stability regulation of hypoxia inducible factor- $1 \alpha$ (HIF-1 $\alpha)$," Current Medicinal Chemistry, vol. 10, no. 10, pp. 845-855, 2003.

[72] S. Nallamshetty, S. Y. Chan, and J. Loscalzo, "Hypoxia: a master regulator of microRNA biogenesis and activity," Free Radical Biology \& Medicine, vol. 64, pp. 20-30, 2013. 


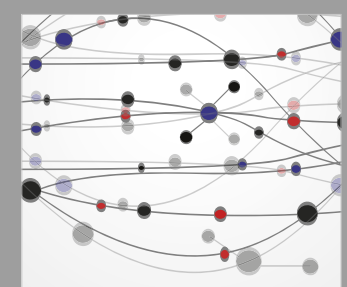

The Scientific World Journal
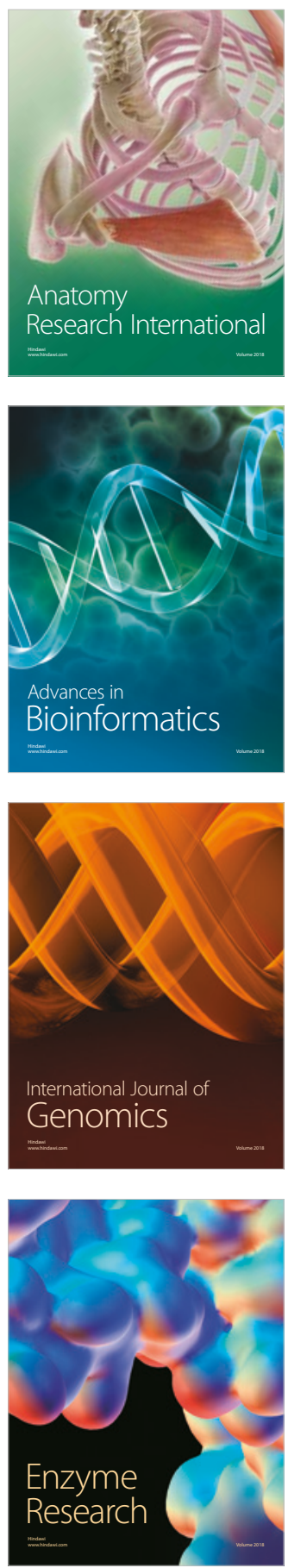
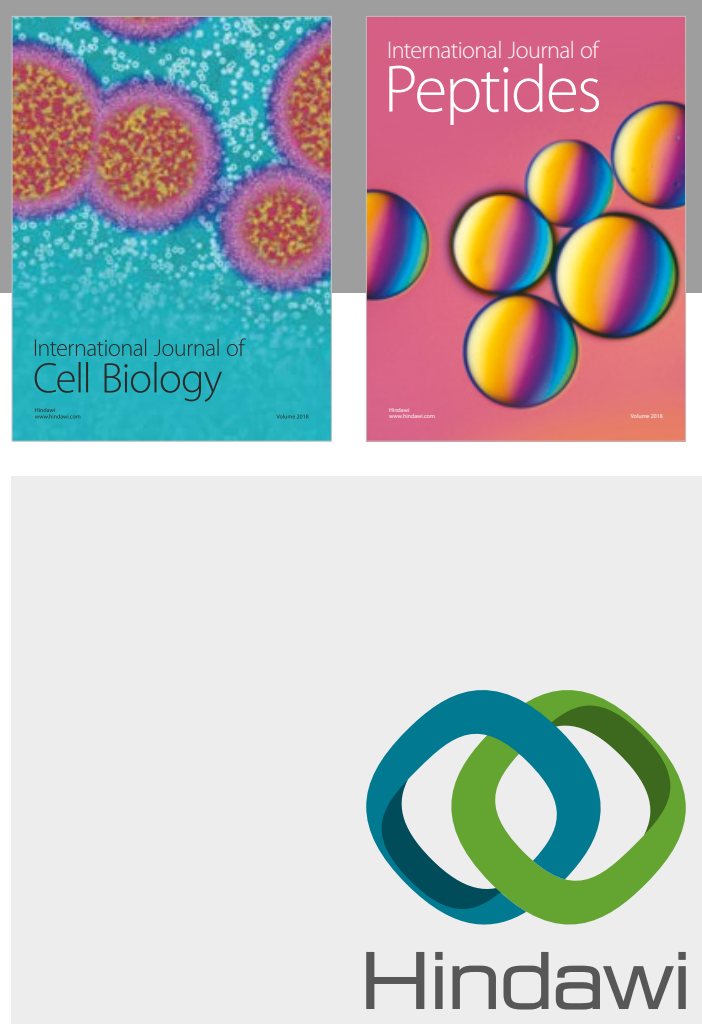

Submit your manuscripts at

www.hindawi.com
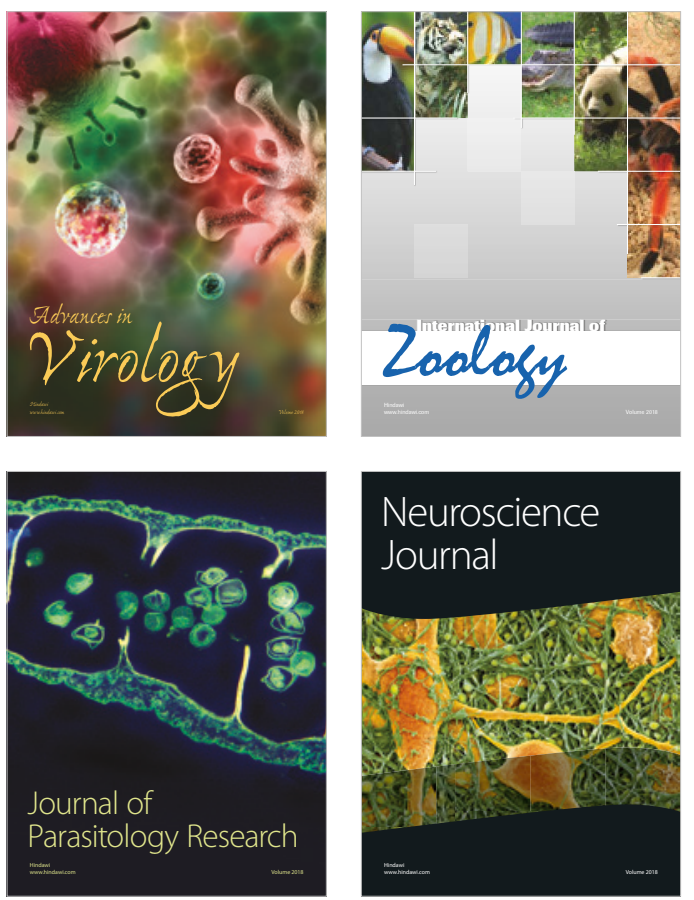
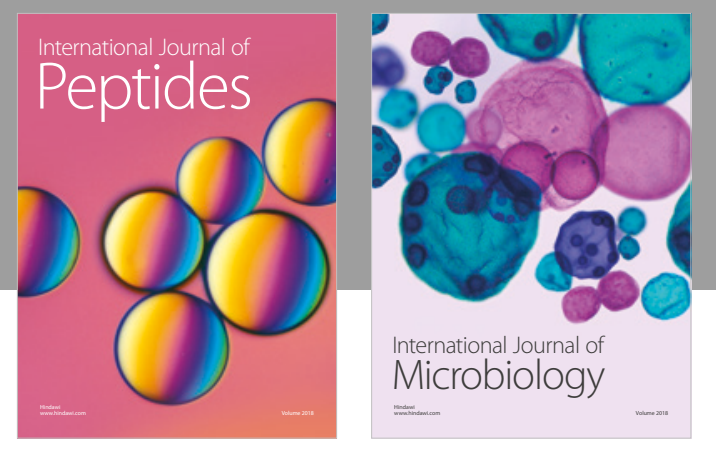

nternational Journal of Microbiology
Journal of
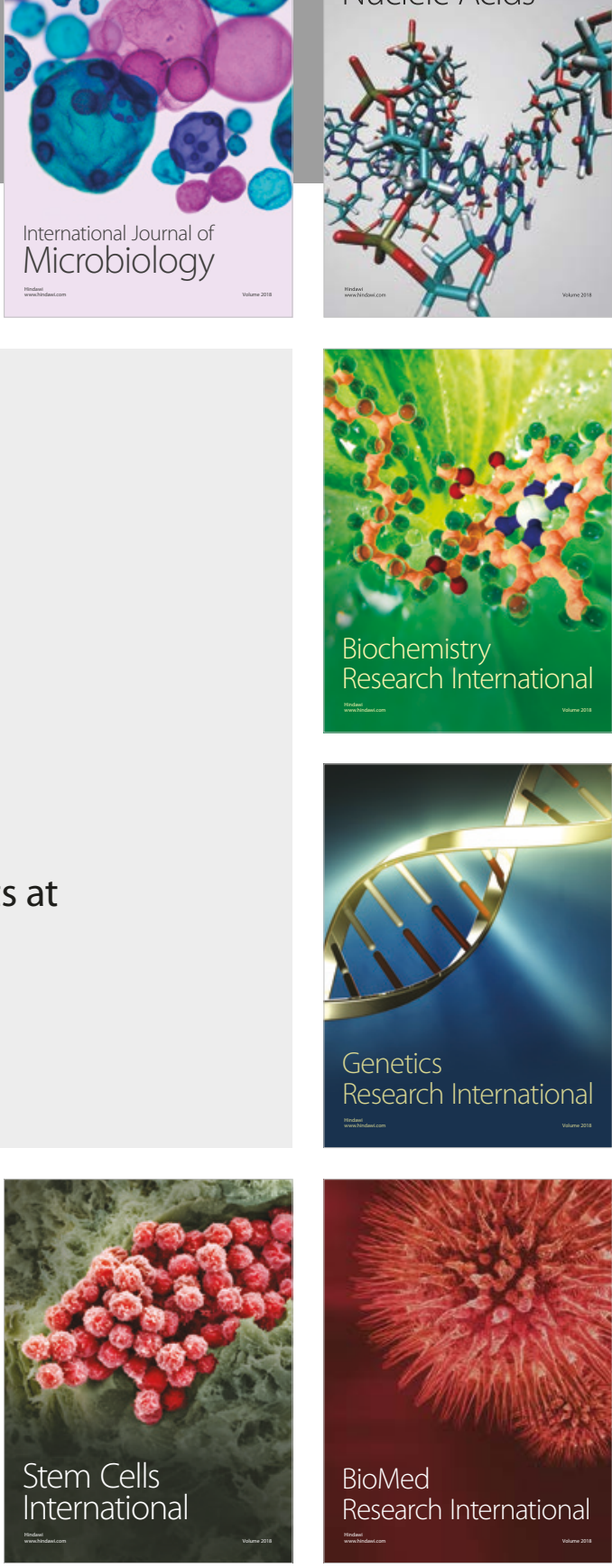
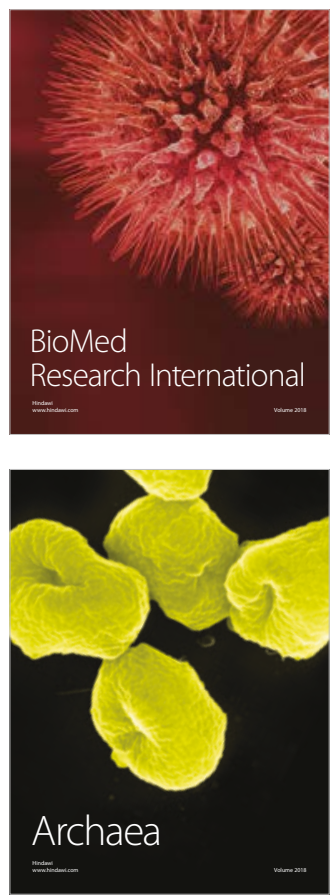